\title{
A EDUCAÇÃO FÍSICA ESCOLAR EM UMA PERSPECTIVA CULTURAL E SUA INTERFACE COM O LAZER
}

\author{
SCHOOL PHYSICAL EDUCATION FROM A CULTURAL PERSPECTIVE \\ AND ITS INTERFACE WITH LEISURE
}

\section{LA EDUCACIÓN FÍSICA ESCOLAR DESDE UNA PERSPECTIVA CULTURAL Y SU INTERFAZ CON EL OCIO}

\author{
Vinicius Aparecido Galindo \\ https://orcid.org/0000-0003-0123-6093 (DD \\ http://lattes.cnpq.br/5327249069736591 \\ Centro Universitário do Norte Paulista (São José do Rio Preto, SP - Brasil) \\ viniciusgalindo@yahoo.com.br
}

\begin{abstract}
Resumo
Este estudo tem como objetivo a humanização do processo de aprendizagem com o intuito de ampliar o repertório das ações pedagógicas do professor por meio das aulas de Educação Física em uma perspectiva cultural, no sentido da educação para o lazer. A Educação Física escolar por meio da educação para o lazer deverá ser um espaço para transformação e observação de princípios e valores, possibilitando aos educandos reflexões críticas e criativas para além da escola. No percurso metodológico, realizamos uma pesquisa qualitativa de natureza bibliográfica, a partir de obras relativas à educação física, cultura e lazer. Para os estudos das obras investigadas, realizamos as análises textual, temática, interpretativa e crítica. É essencial o desenvolvimento da Educação Física com sentido e significado para quem está aprendendo, visando a uma educação para o lazer articulando os saberes locais com os globais em todas as esferas humanas.
\end{abstract}

Palavras-chave: Educação Física Escolar; Lazer; Cultura.

\begin{abstract}
This study aims at humanizing the learning process in order to expand the repertoire of pedagogical actions of teachers through Physical Education classes in a cultural perspective, in the sense of education for leisure. School Physical Education through education for leisure should be a space for transformation and observation of principles and values, allowing students to reflect critically and creatively beyond the school. In the methodological approach, we conducted a qualitative research of a bibliographic nature, based on research related to physical education, culture and leisure. For the studies of the investigated works, we carried out textual, thematic, interpretative and critical analysis. It is essential to develop Physical Education with meaning and significance to those who are learning, aiming at an education for leisure, articulating local knowledge with global knowledge in all human spheres.
\end{abstract}

Keywords: School Physical Education; Recreation; Culture.

\section{Resumen}

Este estudio tiene como objetivo humanizar el proceso de aprendizaje con el fin de ampliar el repertorio de acciones pedagógicas del docente a través de clases de Educación Física en una perspectiva cultural, en el sentido de educación para el ocio. La Educación Física Escolar a través de la educación para el ocio debe ser un espacio de transformación y observación de principios y valores, que permita a los alumnos reflexionar de forma crítica y creativa más allá de la escuela. En el camino metodológico, realizamos una investigación cualitativa de carácter bibliográfico, basada en trabajos relacionados con la educación física, la cultura y el ocio. Para los estudios de los trabajos investigados, realizamos análisis textuales, temáticos, interpretativos y críticos. Es fundamental desarrollar la Educación Física con sentido y significado para quienes están aprendiendo, apuntando a una educación para el ocio, articulando el conocimiento local con el conocimiento global en todos los ámbitos humanos.

Palabras clave: Educación Física Escolar; Recreación; Cultura. 


\section{INTRODUÇÃO}

Neste artigo, apresentaremos elementos para o estudo da Educação Física escolar em uma perspectiva cultural, assim como do lazer e da educação e o processo educativo do lazer. Na constante modificação em que o mundo atual se apresenta, impulsionada pelo capitalismo global, a educação precisa promover a construção do saber ao constituir-se como ferramenta de crescimento sociocultural dos sujeitos. O capitalismo global está relacionado a um sistema econômico que visa o lucro e o acúmulo de riquezas, fundamenta-se na propriedade privada dos meios de produção, potencializando a competição acirrada entre os sujeitos na busca do poder, sucesso e riqueza, valorizando-se o individual em detrimento do coletivo. Uma Educação Física escolar numa perspectiva da educação para o lazer pode transformar a realidade dos alunos, desenvolvendo, a autonomia, a criatividade e a criticidade nos sujeitos.

Com o propósito de desenvolver a emancipação do ser humano, uma educação para o lazer, pelo aspecto prazeroso que lhe é inerente, pode se apresentar como rica possibilidade de prática pedagógica na escola. Assim, uma educação para o lazer visa a emancipação humana, o pensamento crítico do contexto social pelo sujeito, evitando-se a exploração entre as pessoas tornando-as independentes e promovendo a solidariedade, a compreensão e o respeito entre os seres humanos.

Segundo Vago (2009, p. 27), o ambiente escolar:

[...] é lugar de circulação das culturas porque tem como responsabilidade realizar o humano direito a um patrimônio por todos produzido: conhecer, fruir e usufruir as culturas diversas produzidas pelos humanos.

Este autor define a instituição de ensino como ambiente em que várias culturas transitam, visto ser herança cultural à disposição de todos. Assim sendo, é possível tomar ciência desse fato para se apossar e disfrutar dessa instituição como direito.

Marcellino (2007, p. 31), ao conceituar o lazer, visualiza-o como uma dimensão da cultura ao entendê-lo como:

A cultura - compreendida no seu sentido mais amplo - vivenciada (praticada ou fruída) no "tempo disponível". O importante, como traço definidor, é o caráter "desinteressado" dessa vivência. Não se busca, pelo menos fundamentalmente, outra recompensa além da satisfação provocada pela situação. A "disponibilidade de tempo" significa possibilidade de opção pela atividade prática ou contemplativa.

Para esse autor, o lazer promove satisfação a quem o vivencia. Ele justifica que essa disponibilidade de tempo a ele dedicada se deve ao fato de que o sujeito tão somente 
escolheu tal atividade prática ou contemplativa levado pelo querer, pela busca do prazer que ela Ihe proporciona. Marcellino (2013) fundamenta, ainda, que, mesmo o ócio, desde que se contraponha à obrigação profissional, é considerado como opção de lazer. O autor relata que, numa relação dialética entre lazer e sociedade, a cultura por ela gerada pode ser questionada por ela mesma. Outra característica do lazer é a possibilidade de serem vivenciados valores que, de acordo com Marcellino (2013, p. 15), poderão "[...] contribuir para mudanças de ordem moral e cultural, necessárias para solapar a estrutura social vigente".

Assim, cabe enfatizar que o lazer, observado de uma forma questionadora contra os mecanismos de conformação social, é um instrumento de resistência à ideologia dominante e favorece o desenvolvimento cultural e social, com o objetivo de humanizar a sociedade como um todo acerca da sua realidade.

Para Marcellino (2007, p. 59):

O lazer é um veículo privilegiado de educação, e para a prática positiva das atividades de lazer são necessários o aprendizado, o estímulo e a iniciação, que possibilitem a passagem de níveis menos elaborados, simples, para níveis mais elaborados, complexos, com o enriquecimento do espírito crítico, na prática ou na observação. Verifica-se assim, um duplo processo educativo - o lazer como veículo e como objeto de educação.

O lazer como veículo de educação, ou seja, a educação pelo lazer tem como propósito: o prazer, o relaxamento e a interpretação da realidade, responsáveis pelo desenvolvimento social do ser humano. Já o lazer como objeto da educação, isto é, a educação para o lazer, busca a emancipação e o pensamento crítico da realidade pelo sujeito. Ao considerar os aspectos práticos e educativos no âmbito do lazer, obtém-se a abertura para uma ampla visão de mundo, com a perspectiva de intervenção, visto que é sujeito de ação - benefício do caráter de protagonismo que está lhe confere. Ao interpretar e compreender o lazer, consideram-se os seus conteúdos de acordo com Dumazedier (1972): físico-esportivo (práticas esportivas, jogos, brincadeiras, caminhadas), artísticos (pintura, música, escultura, cinema), intelectuais (leitura, pesquisa), manuais (artesanato, jardinagem), sociais (festas, bailes). Além desses, Camargo (1986) destaca uma área de interesse cultural no lazer, o turístico (passeios, viagens); Schwartz e Moreira (2007) sugerem a inserção do conteúdo virtual (computadores, vídeo game, celulares) do lazer, cujo espaço permite novas opções, possibilitando novos significados para a vivência do lazer. Já Fraga e Lopes da Silva (2010) recomendam que é necessário refletir sobre o meio virtual como veículo oportuno para o acesso aos diversos conteúdos do lazer. 
Convém esclarecer que, ainda desenvolvendo a compreensão sobre os conteúdos do lazer, é essencial considerar que a possibilidade de diferentes vivências contribui para uma visão ampla do lazer. Há uma diversidade de vivências nesse sentido, como, por exemplo: participar de uma brincadeira, de um jogo, de uma prática esportiva, ir ao cinema, participar de uma mostra cultural, de oficinas de pintura, de atividades de paisagismo, dentre outras. Nos dias atuais, ao analisarmos a Educação Física fundamentada em uma perspectiva cultural, consideramos a cultura como principal conceito para a Educação Física, porque, segundo Daolio (2004, p. 9): "todas as manifestações corporais humanas são geradas na dinâmica cultural, desde os primórdios da evolução até hoje, expressando-se diversificadamente e com significados próprios no contexto de grupos culturais específicos."

Ou seja, esse autor considera a Educação Física como componente curricular, e o ambiente escolar, como um espaço para desenvolvimento da cultura, contribuindo para a compreensão do educando dos conteúdos culturais relacionados à dimensão cultural, como por exemplo: os jogos, as brincadeiras, os esportes, as ginásticas, as lutas, as danças etc., e, a partir da assimilação desses conteúdos, o educando irá desenvolver seus processos de aprendizagem. Esse mesmo autor não quer padronizar comportamentos, planejamentos rigorosos ou metas de ensino, mas propor um ensino diferenciado por meio de processos de aprendizagem significativos, influenciados pelas dinâmicas culturais, com o intuito de atingir a todos os alunos.

Destaca-se a possibilidade de a escola constituir-se como opção de espaço para o desenvolvimento dos conteúdos de lazer nas aulas de Educação Física ao valorizar a riqueza de experiências culturais da comunidade conforme o seu contexto social. Assim, é possível compartilhar com pais ou responsáveis, educandos e comunidade em geral as diversas experiências educativas desenvolvidas no processo de aprendizagem no período do contraturno ou nos finais de semana.

Nesse contexto, o presente trabalho tem como objetivo a humanização do processo de aprendizagem com o intuito de ampliar o repertório das ações pedagógicas do professor por meio das aulas de Educação Física escolar em uma perspectiva cultural, no sentido da educação para o lazer.

\section{METODOLOGIA}


Este estudo é resultante de uma pesquisa qualitativa. A investigação desse tipo de pesquisa, para Minayo (1994, p. 21), tem características:

[...] muito particulares. Ela se preocupa, nas ciências sociais com o nível de realidade que não pode ser quantificado. Ou seja, ela trabalha com o universo de significados, motivos, aspirações, crenças, valores e atitudes, o que corresponde a um espaço mais profundo das relações, dos processos e dos fenômenos que não podem ser reduzidos à operacionalização de variáveis.

O presente artigo foi desenvolvido por meio de revisão bibliográfica, fundamentada por Severino (2007), a partir de buscas realizadas nos sistemas de biblioteca da Universidade Metodista de Piracicaba (UNIMEP) e em ferramentas disponíveis na internet, utilizando-se as palavras-chave lazer, cultura e educação física escolar. Uma pesquisa de natureza bibliográfica busca esclarecer uma problemática por meio de referenciais teóricos publicados. Isto é, na realização desta pesquisa, foram consultadas obras como artigos, livros e periódicos eletrônicos, articulando-se as ideias sobre à temática desenvolvida e que se alinhassem no cumprimento do objetivo desta investigação (RAMPAZZO, 2002).

Além das obras conhecidas na condição de professor-pesquisador, considerou-se como critério de inclusão aquelas que tinham aproximação com as finalidades da pesquisa, explícitos em seus títulos. Este artigo é um recorte de uma pesquisa maior, desenvolvida em nível de mestrado, intitulada: "Lazer e cultura: construção de brinquedos nas aulas de Educação Física", junto ao Programa de Pós-Graduação em Ciências do Movimento Humano (PPG-CMH) da UNIMEP localizada no interior do estado de São Paulo.

Segundo Severino (2007, p. 122), esse tipo de pesquisa tem como característica: "Aquela que se realiza a partir do registro disponível, decorrente de pesquisas anteriores, em documentos impressos, como livros, artigos, teses e etc." Esse autor cita quatro procedimentos de análise necessários à compreensão dos textos selecionados para esta pesquisa, a saber: 1) análise textual, a qual considera o momento que se constitui em buscar informações sobre os autores e observar o vocabulário dos textos; 2) análise temática: procura-se ouvir os autores, aprender sem intervir no conteúdo descoberto e interpretar no texto o problema que os autores estão mencionando; 3) análise interpretativa: compreendem-se as ideias dos autores, por meio de uma leitura analítica, que favorece o amadurecimento intelectual; 4) análise crítica: inicia-se por meio da problematização dos textos e de questionamentos às mensagens dos autores (SEVERINO, 2007). 
Assim, justifica-se a análise e a interpretação desse tipo de investigação para a temática abordada neste estudo, na tentativa de pesquisar a Educação Física escolar em uma perspectiva cultural no sentido da educação para o lazer.

\section{EDUCAÇÃO INTERCULTURAL E A PEDAGOGIA DA ANIMAÇÃO}

Para Oliveira e Daolio (2011), valorizar as diferenças é dar novo significado às ações e às concepções pedagógicas, com o intuito de solucionar os problemas do sistema tradicional escolar, pautado na exclusão, que foi incapaz, no decorrer do processo educativo, de lidar com as diferenças. Esse autor ressalta que os processos educativos, desenvolvidos num sentido de via única, caracterizam-se numa pedagogia da homogeneização, já que, na visão do professor, todos são iguais, ignorando a diversidade manifestada pelas diferentes culturas e contextos dos alunos.

Consideram-se tais contextos na elaboração dos processos educativos, isto é, vinculá-los à cultura da comunidade local, numa relação que não seja centralizada no educador de uma forma tradicional, poderá contribuir para evitar a exclusão e a evasão de alunos, que, infelizmente, ocorrem na escola. Essa valorização do ser humano em seu contexto sociocultural no ambiente escolar promove a abertura para o diálogo e a reflexão entre as diferentes culturas, possibilitando o acesso ao conhecimento e à informação, além de favorecer o compartilhamento de valores e de atitudes que propiciam a comunicação entre os diferentes.

A eficiência dessa comunicação, graças à diversidade cultural dentro do ambiente escolar que visa à valorização e ao respeito às diferenças culturais, possibilita uma socialização (interação) entre as diversas culturas, ao ressignificar os processos de aprendizagem, promovendo uma educação intercultural. Oliveira e Daolio (2011, p. 4) afirmam que:

A educação intercultural calca seus pressupostos, os quais apontam, não somente para a existência das diferenças, mas também para seu enlace com a aprendizagem, fazendo com que o educando aprenda o conhecimento do outro, do diferente e com ele estabeleça um diálogo profícuo e mútuo, no qual as possibilidades não se encerram a partir de uma única visão.

A educação intercultural coopera para o desenvolvimento dos processos educativos que facilitem a socialização entre as diferentes culturas, já que reconhece o conhecimento do outro como diferente e tem a intenção de valorizá-lo. Na escola, valorizar e reconhecer o diferente constitui aquisição de cultura, e só um processo educativo 
democrático pode viabilizar a prática do diálogo e da reflexão entre elas. Oliveira e Daolio (2011, p. 3) propõem:

A perspectiva intercultural de educação que lança mão de argumentos que caminham no sentido da compreensão de que, para além da simples constatação de diversas culturas, estas precisam dialogar em pé de igualdade.

Esses autores consideram a visão da pluralidade de culturas na educação, compreendendo que, além de identificar tal diversidade, é fundamental abordá-las com a relevância de igualdade. Ou seja, são as condições igualitárias que poderão acrescentar intelectualmente e culturalmente ao cidadão. Tal enriquecimento pode ser alcançado com novos arranjos pedagógicos que valorizem o conhecimento prévio do educando, atividades diversificadas vinculadas ao seu contexto social, aliadas ao processo de aprendizagem.

Marcellino (2007, p. 108) afirma que "as relações lazer-escola-processo educativo, como um dos canais possíveis de atuação no plano cultural, buscando mudanças de ordem social". A experiência do lazer na escola alinhada ao processo educativo potencializa valores sociais democráticos de inclusão social e de igualdade, que, diante do mundo moderno, são um dos desafios da sociedade atual. Para o mesmo autor, Marcellino (2007, p. 142), é preciso reconhecer a relação lazer-escola-processo educativo, numa "pedagogia da animação":

[...] em que a animação engloba os sentidos de vida, de movimento e de alegria. Portanto, uma pedagogia da animação, assim encarada, estaria ligada à criação de ânimo, à provocação de estímulos, e à cobrança da esperança. A preparação não para uma sociedade dominada pela exploração do trabalho, ou para o ideal questionável de uma "civilização do lazer".

A pedagogia da animação na instituição de ensino deve ser observada numa perspectiva de mudança, articulada a um processo amplo de educação, visando ao despertar para a alegria de viver ativamente no seu cotidiano, de modo a considerar a escola como espaço para o desenvolvimento das potencialidades educativas do lazer e como oportunidade de transformação do contexto social. Nesse ambiente educativo que pode capacitar uma sociedade a lutar sem qualquer dominação, Marcellino (2012) trata a educação para o lazer como uma proposta denominada Pedagogia da Animação, em que ânimo, esperança e estímulo seriam seus sustentáculos na busca de mudanças de ordem social. Nesse sentido, Marcellino (2007, p. 147, grifos do autor) relata que a perspectiva da pedagogia da animação na escola funcionaria como centro de cultura popular:

Sua tarefa educativa seria efetuada, em termos de conteúdo, a partir do cotidiano local, fornecendo instrumental necessário no sentido de contribuir para a superação do "senso comum", a partir dele. E isso poderia ocorrer mesmo na atual organização curricular - o que vale dizer- mesmo sem as 
condições ideais, que implicariam numa mudança da estrutura dos currículos. Em termos de forma, respeitando o ritmo dos alunos, mas não ignorando as diferenças na apropriação do saber entre professores e alunos, uma vez que esse reconhecimento é necessário para a própria superação dessas diferenças. Em termos de abrangência, ultrapassando o âmbito dos alunos "regularmente matriculados", mas se estendendo a toda a comunidade local, através da participação comunitária. Em termos de espaço, ultrapassando os limites dos muros dos prédios escolares, estendendo-se a outros equipamentos da comunidade próxima, procurando dessacralizá-los. Em termos de elementos humanos, por um grupo de educadores, englobando professores, funcionários, administradores, lideranças culturais informais, práticos nas diversas áreas culturais, enfim um grupo de animadores culturais, que aliem competência técnica-acadêmica ou prática - a um compromisso político de transformação. Em termos de recursos materiais, procurando utilizar os parcos que lhe são destinados, aliados a soluções alternativas da própria comunidade local [...]".

Isto é, uma escola como centro de cultura popular baseada pelo seu Projeto Político Pedagógico (PPP) e articulada com a comunidade local deve, acerca dessa realidade, criar um ambiente favorável para o desenvolvimento de um instrumento que busque auxílio para a superação do senso comum, do convencional. Mesmo sem as condições ideais que implicariam a mudança da estrutura dos currículos, essa tarefa educativa seria efetuada.

Motivado por esse empenho, o educador pode, enfim, respeitando o ritmo dos educandos e não ignorando as diferentes fases sensíveis de aprendizagem, reconhecer as diferenças que trazem consigo. Para nortear as tomadas de atitude objetivadas nesse enfoque cultural, ao oportunizar as ações pedagógicas alinhadas ao lazer nas aulas de Educação Física, é preciso considerar o ambiente educativo e os sujeitos nele envolvidos. Considera-se a escola, assim, como espaço privilegiado para transformação, observação e manifestação de princípios e de valores, de modo que os educandos possam transferir as reflexões para além da instituição de ensino, atendendo a toda a comunidade local. A participação coletiva da equipe pedagógica (gestores, coordenadores, educadores, funcionários, pais, alunos e comunidade) pode se formar em um grupo de animadores culturais, que articulem competência prática ao compromisso político de transformação. Para tanto, devem ser adequados os diversos espaços e recursos materiais, buscando soluções alternativas ao realizar parcerias com a comunidade local acerca da sua realidade.

Para Vago (2009), a escola é um lugar de culturas em que adultos, adolescentes e crianças promovem cultura infantil, juvenil e adulta. Nelas estão envolvidas suas etnias, suas classes sociais, seu gênero, sua orientação sexual e as marcas de suas histórias, significantes 
para suas vidas, isto é, na escola, esses protagonistas se encontram e criam formas de produzir saberes, seus modos de ser e de estar, compartilhar sentimentos e experiências.

Refletir sobre a escola como espaço e momento de cultura é humanizar o processo de aprendizagem, visto que, no ambiente escolar, acontece a produção de conhecimento. Assim, é reconhecer que na diversidade todos os seus protagonistas, adultos, jovens, adolescentes e crianças, promovem cultura. Além disso, para refletir sobre a prática educativa, torna-se imprescindível destacar a relevância da pedagogia da animação apresentada por Marcellino (2007). Nessa proposta pedagógica, o autor propõe a possibilidade do lazer como um canal viável no plano cultural de modo integrado com a instituição de ensino, visando a contribuir para a reflexão e o espírito crítico numa perspectiva da realidade social. Segundo Marcellino (2007, p. 149):

No plano cultural seria orientada por princípios de valorização da cultura popular, em todas as áreas analisadas- artística, física, manual, social e intelectual- o que vale dizer, buscando o equilíbrio entre os vários conteúdos, e a sua identificação com as bases locais e regionais. No plano social seria orientada para o atendimento com critérios quantitativos, procurando atender o maior número de pessoas a partir de seus interesses, o que não significa "nivelar por baixo", mas iniciar o trabalho educativo a partir das situações reais; procurando recursos materiais alternativos e exercendo pressões para obtenção de novos recursos; procurando, sem preconceitos ideológicos, articulações com órgãos e instituições locais, na medida em que possam ser estabelecidas, sem que se abra mão do compromisso de mudança da situação, portanto do compromisso político.

Esse autor compreende que se deve valorizar a cultura popular em todas as áreas: artística, física, manual, social e intelectual. Isso equivale a considerar o equilíbrio entre os diversos conteúdos do lazer e os contextos local e regional. Já no plano social, ele esclarece que a proposta é atender com valorização do quantitativo. A partir de suas necessidades, iniciar um trabalho de cunho educativo considerando a realidade do contexto em que se vive, buscando desenvolver novas opções de recursos materiais e esforçando-se na procura de outros recursos; pretendendo ter, sem discriminação, parcerias com entidades sociais, com o propósito de que, sendo estabelecidas, promovam emancipação social.

Com esse objetivo, a cultura é reconhecida pela interdependência entre o lazer, a escola, o processo educativo, o educando, a família e o contexto social, já que a escola dinâmica é aquela que se aproxima da realidade local. Assim sendo, é fundamental fazer inovações metodológicas nas práticas educativas, considerando-se as possibilidades do lazer, 
conectando-a com a cultura, que visa não só a uma educação de qualidade alicerçada no ambiente escolar, mas uma educação com qualidade social.

As aulas de Educação Física alinhadas à educação para o lazer podem contribuir para uma educação escolar que prioriza a produção cultural com o intuito de transformar a realidade social. Assim, constituem-se em ações que poderão viabilizar a transformação dos alunos, com propósito de desenvolverem a autonomia, a criticidade e a criatividade em articulação com os saberes locais e regionais. No próximo tópico, são apresentados aspectos da Educação Física escolar e da educação para o lazer.

\section{EDUCAÇÃO FíSICA ESCOLAR NO SENTIDO DA EDUCAÇÃO PARA O LAZER}

Uma Educação Física escolar em uma perspectiva cultural com vistas à humanização, igualitária, que busca a conscientização do lazer na perspectiva de construção da cultura corporal de movimento contemporâneo, é de suma importância para a formação do sujeito no ambiente escolar. Ela pode ser considerada uma ação construída pelos significados e valores inerentes ao contexto social na escola, possibilitando o desenvolvimento de atividades do contexto do lazer significativas no tempo disponível. $\mathrm{Na}$ busca de se incentivar a perspectiva do lazer, a Educação Física deve evidenciar por um ambiente em que se constrói conhecimento a partir de relações sociais, evitando qualquer tipo de exclusão, com o intuito do desenvolvimento de práticas educativas com relevância no processo de aprendizagem e na formação humana, em uma dimensão sociocultural.

De acordo com Daolio (1994), em uma abordagem cultural, alicerçada na Antropologia Social, a ciência antropológica considera a humanidade plural e busca abordar os seres humanos a partir das suas diferenças. Isto é, um novo olhar pode propor uma revisão da prática pedagógica da Educação Física escolar, a prática do "rola bola", pautada na atualidade, em muitas escolas, em que o professor, permite a seus educandos realizarem a atividade livremente, sem sua intervenção pedagógica ou a valorização dos alunos mais habilidosos em relação aos menos habilidosos, excluindo-os. É essencial que se volte para uma perspectiva inovadora, em que se fundamentem as ações pedagógicas que possam se abrir para a diversidade por meio da cultura corporal de movimento.

Para Daolio (1994, p. 30), a antropologia nos ensina a evitar qualquer tipo de preconceito ou discriminação: 
Uma vez que todo comportamento humano, por possuir uma dimensão pública, não pode ser julgado por meio de conceitos implacáveis como bom/mau ou certo/errado. O entendimento de qualquer atitude humana deve ser buscado em referenciais culturais que dão sentido a essas atitudes. Como vimos, o chamado "olhar antropológico" implica uma relação espetacular entre quem olha e quem é olhado. Olhar para o outro é, em alguma medida, olhar para si mesmo através do outro, por que a forma de olhar é também influenciada pela cultura.

Observa-se que, romper a barreira do preconceito e considerar que todos os seres humanos são iguais com culturas diferentes, pode favorecer a abertura para a diversidade e isso contribuirá para a transformação social e para a emancipação dos sujeitos. Esse novo olhar que a Antropologia propõe, conforme Daolio (1994, p. 100), beneficia uma Educação Física escolar que considera o princípio da alteridade ao afirmar que o educador, na aula:

[...] saberá reconhecer as diferenças: não só físicas, mas também culturaisexpressas pelos alunos, garantindo assim o direito de todos à sua prática. A diferença deixará de ser critério para justificar preconceitos, que causam constrangimentos e levam a subjugação dos alunos, para se tornar condição de sua igualdade, garantindo assim, a afirmação do seu direito à diferença, condição do pleno exercício da cidadania. Porque os homens são iguais justamente pelas suas diferenças.

Ou seja, valorizar a diversidade é promover a abertura às múltiplas expressões de cultura, repudiando qualquer tipo de preconceito ou de discriminação, garantindo o princípio da igualdade-equidade entre os seres humanos.

Segundo Pinto (1992, p. 292), para lidar com a diversidade:

A educação física precisa compreender, construir, avançando conhecimentos sobre a essência orgânica e cultural das diferentes linguagens do corpo, que se manifestam de várias formas [...]. É importante identificar e compreender as estruturas e significados das diferentes manifestações da cultura corporal de movimentos, esforçando-se por compreender seus sentidos e importância para a vida do ser e para as suas relações culturais, historicamente estabelecidas.

Nessa perspectiva, cabe ao professor de Educação Física, nas suas ações pedagógicas no interior da escola, promover uma educação para o lazer valorizando a diversidade, que propicie ao educando a alegria e a compreensão acerca da realidade com o intuito de transformar o contexto social do sujeito. Na dinâmica das atividades articuladas com os conteúdos do lazer, como o conteúdo físico-esportivo (práticas esportivas, jogos, brincadeiras, caminhadas), criar condições para a resolução conjunta de situações-problema, o professor pode formar um ambiente facilitador à conscientização de uma visão crítica nos educandos sobre o meio em que estão envolvidos, na busca do desenvolvimento de sua 
autonomia para resolver problemas, transformar sua realidade social etc. O acesso ao lazer implica uma educação de sujeitos capazes de interpretar e de vivenciar oportunidades diversificadas e disponíveis nos tempos e nos espaços, dia após dia. Assim, criam-se condições de compreendê-las e de ressignificá-las de forma consciente, compreendendo a sua importância em suas vidas e as condições que restringem sua vivência plena (PINTO, 2008).

Observa-se que a educação pode contribuir para a emancipação do cidadão no desenvolvimento de suas potencialidades, ao obter uma postura crítica e autônoma diante dos problemas sociais. Isso garante um nível cada vez mais elaborado de acesso ao lazer e estabelece interações culturais efetivas entre o espaço escolar e o contexto sociocultural. O educador que articula a Educação Física escolar e a educação para o lazer no processo educativo valorizará a potencialidade do lazer no desenvolvimento pessoal e social e a importância do aprendizado para utilizá-lo no tempo disponível. Ou seja, basta que reconheça a cultura dos educandos, exercendo sua função de mediador e incentivando a participação dos alunos por meio de ações pedagógicas na perspectiva de sensibilizá-los nas diversas experiências educativas. Segundo Pinto (2008, p. 49), a educação pelo e para o lazer se efetiva:

[...] pela função política quando se vincula à realidade social, às possibilidades de compreensão desta realidade e de acesso a outros modos de conhecê-la e de nela agir com liberdade de expressão e de trocas de experiências entre diferentes sujeitos e grupos neste processo. A função ética desse processo educativo é constituída pela autonomia dos sujeitos e grupos no lazer, com liberdade e responsabilidade. Nesse sentido, o processo educativo estimula o desenvolvimento de atitudes e valores como tolerância, justiça, cooperação, solidariedade, respeito mútuo, confiança e outros. Já na função estética alicerça-se no desenvolvimento da sensibilidade, autoconhecimento, reconhecimento e valorização da diversidade cultural.

Na visão desta autora, a educação para e pelo lazer realiza-se pela função política quando o educador considera os meios do contexto em que atua e promove o diálogo, a interação entre os alunos. Já na função estética, busca-se reconhecer os méritos da sua cultura e da cultura do outro. Ainda é Pinto (2008, p. 51) quem afirma que, "[...] a educação para e pelo lazer é um processo de construção continuada que não deve ser tratado da mesma maneira ao longo da vida". Sabe-se que uma ação educativa qualitativa, efetiva, considerando os diferentes contextos, propicia ao educando a apropriação de conhecimentos, de competências, de habilidades, dentre outros, que se constituem em 
conteúdos socialmente acumulados historicamente do sujeito, contribuindo para o desenvolvimento pleno do aluno.

Para Pinto (2008), relacionar o conhecimento prévio, problematizando e promovendo sentido às ações educativas pelo educando no processo de aprendizagem, intervindo por meio do diálogo, aumentam as possibilidades de acesso às atividades educativas realizadas. A autora comenta que o diálogo é uma ferramenta educativa que estabelece relações entre o vivido e o proposto, o real e o subjetivo, os desejos e as necessidades. Isto é, por meio do diálogo, o professor valoriza o conhecimento que o aluno traz para a escola, aproximando-o dos conteúdos de aprendizagem, o que facilita a aprendizagem do educando, consolidando uma prática educativa significativa. Essa ação é fundamentada por Vago (2009, p. 36), que discute a importância da intervenção pedagógica do educador:

Organizar o ensino de modo que seus alunos possam ter realizado o direito de acesso àquelas práticas, usufruindo um patrimônio cultural que a todos pertence. E incentivando também que eles possam, ao participar delas, compreendê-las, fazer crítica delas e, quando for o caso, imprimir-lhes outros significados, baseados especialmente na igualdade de oportunidades, no respeito, na troca solidária, na cooperação, na partilha de afetos.

Ou seja, a educação para o lazer, que pode ocorrer tanto na aula de Educação Física como em espaços de lazer utilizados no tempo disponível, efetiva-se pelo diálogo do professor com seus alunos. Seu objetivo é de levá-los a refletirem, bem como de desenvolverem sua criatividade, autonomia e criticidade. A educação pelo lazer pode ocorrer somente em espaços de lazer vivenciados no tempo disponível.

A participação de todos (educandos e educadores) na criação de vínculos, na elaboração de ideias, no compartilhar de conhecimentos, nas combinações dos conteúdos e de regras de convivência caracteriza esse processo educativo. Ele enriquece o aluno por meio de diferentes experiências, afetivas, éticas, cognitivas, sociais, simbólicas, estéticas e culturais, ou seja, é significativa a possibilidade de múltiplas vivências realizadas.

A Educação Física, em uma perspectiva cultural, promove a abertura para a diversidade, ou seja, para o diálogo, a reflexão e o respeito pelo diferente, que valoriza a diversidade cultural e o conhecimento prévio que o aluno traz para o ambiente escolar. Além disso, promover atividades diversificadas relacionadas aos conteúdos do lazer nas aulas de Educação Física envolve socialização, cooperação, trabalho coletivo, criatividade e habilidades 
fundamentais para a formação do cidadão, produzindo conhecimento novo por meio da ação lúdica e tendo como finalidade a educação para o lazer.

\section{CONSIDERAÇÕES FINAIS}

A Educação Física escolar deve considerar o aspecto cultural de suas vivências prática. Assim, explorar as diferentes culturas dos alunos pode fundamentar uma prática nas aulas de Educação Física que promova a transformação acerca do contexto dos sujeitos. Ou seja, respeitar a cultura de movimento do educando possibilita o acesso a diversos tipos de experiências e propicia a abertura para a diversidade de outras culturas.

Além disso, a escola também pode contribuir de modo efetivo com a transformação social da comunidade local. Para tanto, é preciso alinhar as ideias de acordo com o contexto social no qual está inserida, por meio de ações educativas como forma de incentivo e com o aumento da prática de atividades diversificadas, mobilizando saberes para os alunos com o propósito de ultrapassar os muros escolares.

Nota-se que valorizar a instituição de ensino por meio de uma Educação Física em uma perspectiva cultural no sentido da educação para o lazer, isto é, como um espaço de construção do saber, viabiliza o acesso às diferentes culturas produzidas pelos sujeitos, para o desenvolvimento de suas potencialidades. Educadores e educandos são sujeitos da própria história e se relacionam entre si, compartilhando diferentes vivencias para propagação da autonomia, da criatividade, da criticidade e da cultura em todas as esferas sociais.

Espera-se, com este estudo, que o educador, na contemporaneidade, considere que a Educação Física escolar possa ser acessível a todos, ao atuar coletivamente em uma perspectiva cultural na escola, que vise, sobretudo, à transformação da comunidade local. Além disso, possa viabilizar aos educandos uma educação para o lazer com valorização de sua bagagem cultural, e que seu aprendizado seja enriquecido, a partir de um trabalho diversificado nas aulas de Educação Física, de modo a propor aos alunos a revisão de sentidos e de valores socioculturais.

\section{REFERÊNCIAS BIBLIOGRÁFICAS}

CAMARGO, Luiz Octávio de Lima. O que é lazer. São Paulo: Brasiliense, 1986.

DAOLIO, Jocimar. Da cultura do corpo. 2. ed. Campinas: Papirus, 1994. 
Educação Física e o conceito de cultura. 2. ed. Autores Associados, 2004.

DUMAZEDIER, Joffre. Questionamento teórico do lazer. Rio Grande do Sul: Celar/PUCRS, 1972.

FRAGA, Elisangela Aparecida Macedo; LOPES DA SILVA, Cinthia. Comunidades virtuais de internet: atualização do debate sobre lazer. Licere, v. 13, n. 3, p. 1-21, dez., 2010.

MARCELLINO, Nelson Carvalho. Lazer e educação. 12. ed. Campinas, SP: Papirus, 2007.

Pedagogia da animação. 10. ed. Campinas, SP: Papirus, 2012.

. Lúdico, educação e educação física. 4. ed. ljuí, RS: Unijuí, 2013.

MINAYO, Maria Cecília de Souza. Pesquisa social. 21. ed. Petrópolis, RJ: Vozes, 1994.

OLIVEIRA, Rogério Cruz; DAOLIO, Jocimar. Educação intercultural e educação física escolar: possibilidades de encontro. Pensar a prática, v. 14, n. 2, p. 1-11, 2011.

PINTO, Leila Mirtes Santos de Magalhães. A recriação/ lazer no "jogo" da educação física e dos esportes. Revista brasileira de ciências do esporte, v. 12, n. 1, 2, 3, p. 289-293, 1992.

. Lazer e educação: desafios da atualidade. In: MARCELLINO, Nelson Carvalho (Org.).

Lazer e sociedade. Campinas, SP: Alínea, 2008.

RAMPAZZO, Lino. Metodologia científica: para os alunos dos cursos de graduação e pósgraduação. 3. ed. São Paulo: Loyola, 2002.

SEVERINO, Antônio Joaquim. Metodologia do trabalho científico. 21. ed. São Paulo: Cortez, 2007.

SCHWARTZ, Gisele Maria; MOREIRA, Jaqueline Castro Castilho. O ambiente virtual e o lazer. In: MARCELLINO, Nelson Carvalho (Org.). Lazer e cultura. Campinas, SP: Alínea, 2007.

VAGO, Tarcísio Mauro. Pensar a educação física na escola: para uma formação cultural da infância e da juventude. Cadernos de formação RBCE, v. 1, n. 1, p. 25-41, 2009.

Dados do autor:

Email: viniciusgalindo@yahoo.com.br

Endereço: Rua Ipiranga, 3460, Jardim Alto Rio Preto, São José do Rio Preto, SP, CEP: 15020040, Brasil.

Recebido em: 28/02/2021

Aprovado em: 29/03/2021

Como citar este artigo: 
GALINDO, Vinicius Aparecido. A educação física escolar em uma perspectiva cultural e sua interface com o lazer. Corpoconsciência, v. 25, n. 1, p. 187-202, jan./ abr., 2021.

\section{Agradecimento}

À Secretaria da Educação do Estado de São Paulo, pelo financiamento desta pesquisa. 